\title{
Protein binding of warfarin
}

Chan et al. [1], in comparing the results of their study of plasma protein binding of warfarin with one of ours [2], stated that in our study 'no check of radiochemical purity was reported'. That is incorrect. We were the first to point out the importance of assay specificity for plasma protein binding determinations with $\left[{ }^{14} \mathrm{C}\right]$-warfarin [3] and used post-dialysis thin layer chromatographic methodology to separate warfarin from its metabolites and degradation products in all our studies with radiolabeled warfarin. This is evident via reference 18 in our report [2] in which it is clearly stated that warfarin concentrations were determined by scintillation spectrometry following extraction and thin layer chromatography.

We reported in 976 in a publication not cited by Chan et al. [1] a statistically significant negative correlation between the serum free fraction of warfarin and serum albumin concentration in normal subjects [4]. The absence of a significant correlation between serum free fraction and serum protein concentration in our study of patients [2] is likely to be due to concomitant medication and disease state, and not, as Chan et al. [1] have implied, to deficient methodology.

\section{GERHARD LEVY}

Department of Pharmaceutics, 545 Hochstetter Hall, State University of NY at Buffalo, Amherst, New York 14260, USA

Received 25 August 1994, accepted 27 September 1994

\section{References}

1 Chan E, McLachlan AJ, Pegg M, MacKay AD, Cole RB, Rowland M. Disposition of warfarin enantiomers and metabolites in patients during multiple dosing with racwarfarin. Br J clin Pharmac 1994; 37: 563-569.

2 Yacobi A, Udall JA, Levy G. Serum protein binding as a determinant of warfarin body clearance and anticoagulant effect. Clin Pharmac Ther 1976; 19: 552-558.
3 Yacobi A, Levy G. Importance of assay specificity for plasma protein binding determinations. J Pharmacokinet Biopharmaceut 1975; 3: 439-441.

4 Yacobi A, Stoll RG, DiSanto AR, Levy G. Intersubject variation of warfarin binding to protein in serum of normal subjects. Res Commun Chem Path Pharmac 1976; 14: 743-746.

\section{Improving patient recruitment in clinical trials: lessons from one multicentre study in asthma}

Information regarding recruitment in clinical trials is not often formally reported and is therefore limited, most data referring to large multicentre trials $[1,2]$. We report the results of a study aimed at assessing different recruitment strategies from four Spanish centres who were participating in an international trial.

This was an 8 week randomized, double-blind, placebo-controlled, Phase II, dose ranging study of a new drug for the treatment of mild to moderate asthma and was performed over a 3 month period. Several criteria for selecting patients could be expected to affect the ease with which suitable patients could be identified, e.g. FEV ${ }_{1}$ and $\mathrm{FEV}_{1} / \mathrm{FVC}$ ratio (Tiffenau index) to fall within a defined range; symptomatic asthma to be present; previous drug therapy for the asthma especially with regard to inhaled steroid; and the need to exclude women of childbearing potential. The workload for the patients enrolled was considerableseveral pulmonary function tests (PFTs) at each of eight visits, blood sampling at many of them and twice daily recording of symptoms and medication in diary cards.
All investigators, who had experience with similar types of trials, were asked to complete a form in order to collect the following data: total number of medical records reviewed; number of patients appointed for a screening visit; listing of all patients attending a screening visit; reason for non-enrolment where applicable. We considered that a patient was enrolled in the trial after informed consent had been obtained, thus ending recruitment activity [2]. The participating centres were all hospital based. Centre A was a Department of Allergy and Centres B, C and D were Departments of Respiratory Medicine. Centres A and $B$ were less than 500 beds and Centres $C$ and $D$ were more than 1000 beds. The strategies for searching adult patients were as follows: Centre $\mathrm{C}$ (the control centre) just screened asthma patients who were otherwise attending the Out Patient Clinic for a standard visit-the 'wait and see strategy'; Centres A, B and D searched hospital files for asthmatic patients to make a preliminary assessment based on data available in the patients' records, and invited those patients who fulfilled selection criteria to a screening visit. Further- 